$\begin{array}{rr}\text { JURNAL } & \text { Volume } 13 \text {, Nomor 4, Juli } 2017 \\ \text { FIT(1)PATOLOGI } & \text { Halaman } 119-126 \\ \text { I N D O N E S I } & \text { DOI: } 10.14692 / \text { jfi.13.4.119 }\end{array}$

\title{
Sensitivitas Colletotrichum spp. pada Cabai terhadap Benomil, Klorotalonil, Mankozeb, dan Propineb
}

\author{
Sensitivity of Colletotrichum spp. on Chili to Benomyl, Chlorotalonil, \\ Mancozeb, and Propineb
}

Desta Andriani, Suryo Wiyono, Widodo*

Institut Pertanian Bogor, Bogor 16680

\begin{abstract}
ABSTRAK
Pengendalian penyakit antraknosa pada cabai yang disebabkan oleh beberapa spesies Colletotrichum dengan aplikasi fungisida yang intensif menggunakan satu jenis bahan aktif dapat menyebabkan terjadinya resistensi. Resistensi ditandai dengan berkurangnya sensitivitas patogen terhadap fungisida meskipun dengan rekomendasi di atas anjuran. Tujuan penelitian ialah menentukan tingkat sensitivitas 3 spesies Colletotrichum dari cabai terhadap 4 fungisida berbahan aktif benomil, klorotalonil, mankozeb, dan propineb. Pengujian dilakukan menggunakan teknik makanan beracun pada berbagai konsentrasi, yaitu dengan mengukur hambatan relatif diamater koloni Colletotrichum spp. Hasil penelitian menunjukkan bahwa semua isolat Colletotrichum sudah sangat resisten terhadap bahan aktif klorotalonil bahkan pada 10 kali konsentrasi anjuran. Beberapa isolat Colletotrichum memberikan respons resisten sampai sangat resisten tehadap bahan aktif mankozeb dan propineb pada konsentrasi anjuran, walaupun masih sensitif pada 5 kali konsentrasi anjuran. Isolat Colletotrichum yang diuji masih sensitif terhadap bahan aktif benomil.
\end{abstract}

Kata kunci: antraknosa, benomil, klorotalonil, mankozeb, propineb, sensitivitas

\begin{abstract}
Anthracnose caused by several species of Colletotrichum is one of limiting factors for chilli production. Up to now the control of antrachnose disease still rely on regular and intensive application of synthetic fungicides. Application of similar active ingredients of synthetic fungicides may create resistance of the pathogens. This study was conducted to evaluate the sensitivity of three species of Colletotrichum against four commercial fungicides with different active ingredients, i.e. benomyl, chlorotalonil, mancozeb, and propineb. The sensitivity level and the potential occurrence of resistance of Colletotrichum were observed based on relative inhibition rate using poisoning food method. The results showed that all isolates were highly resistant to chlorotalonil, even up to ten times of the highest recommended concentrations. The tested fungal isolates were resistant or highly resistant to the recommended concentrations of mancozeb and propineb, but they were still sensitive when the concentrations were increased up to five times. Isolates of Colletotrichum spp. showed sensitive to highly sensitive response to benomyl.
\end{abstract}

Key words: antrachnose, benomyl, chlorotalonil, mancozeb propineb, sensitivity

*Alamat penulis korespondensi: Departemen Proteksi Tanaman, Fakultas Pertanian, Institut Pertanian Bogor. Jalan Kamper, Kampus Dramaga IPB, Bogor 16680.

Tel: 0251-8629364, Faks: 0251-8629362, Surel: widodo@apps.ipb.ac.id 


\section{PENDAHULUAN}

Cabai merupakan tanaman hortikultura yang mempunyai arti ekonomi tinggi sehingga banyak dibudidayakan di Indonesia. Produktivitas cabai tahun 2014 sebesar 8.37 ton ha $^{-1}$ (BPS 2015) padahal potensi produktivitasnya mampu mencapai 20 ton ha $^{-1}$ (Syukur et al. 2010). Salah satu faktor pembatas dalam produktivitas ialah penyakit antraknosa pada tanaman cabai karena dapat menyebabkan kehilangan hasil mencapai 50\% (Prathiba et al. 2013). Herwidyarti et.al (2013) melaporkan kehilangan hasil produksi cabai di Indonesia sebesar 44\% dengan masa inkubasi cepat; sedangkan menurut Widodo (2007) kehilangan hasil mencapai $80 \%$ dimusim penghujan. Tiga spesies cendawan Colletotrichum yang menginfeksi buah cabai ialah C. gloeosporioides, C. acutatum (Kim et al. 2007), dan C. capsici (Sangdee et al. 2011).

Upaya yang umum dilakukan untuk menanggulangi penyakit ini ialah dengan penggunaan fungisida secara intensif. Saat ini terdapat lebih dari 24 bahan aktif tunggal maupun campuran fungisida yang terdaftar untuk pengendalian penyakit antraknosa pada cabai (Dirjen PSP 2015). Bahan aktif yang umum diaplikasikan di lapangan untuk pengendalian antraknosa ialah klorotalonil, mankozeb, propineb (Suganda et al. 2001), dan benomil yang sering dipakai dalam perlakuan benih (Setiyowati et al. 2007). Keterbatasan pengetahuan petani sering menyebabkan satu jenis fungisida atau bahan aktif yang sama digunakan secara terus-menerus untuk waktu yang lama. Suganda et al. (2001) melaporkan beberapa fungisida tidak direkomendasikan untuk pengendalian penyakit antraknosa pada cabai tetapi diaplikasikan juga pada tanaman.

Penggunaan satu jenis bahan aktif fungisida secara intensif dapat menyebabkan terjadinya mutasi gen patogen sehingga sensitivitasnya terhadap fungisida berkurang (Ziogas et al. 2005). Suganda et al. (2001) melaporkan bahwa tingkat sensitivitas Colletotrichum yang diisolasi dari daerah Cikole Lembang memiliki sensitivitas yang rendah terhadap Cu-hidroksida, difenokonazol, mankozeb, maneb, klorotalonil, dan propineb. Oleh karena itu, perlu ditentukan tingkat sensitivitas terkini dan kemungkinan munculnya ketahanan beberapa spesies Colletotrichum penyebab antraknosa cabai terhadap benomil, klorotalonil, mankozeb, dan propineb di sentra penanaman cabai di Pulau Jawa dan Sumatera.

\section{BAHAN DAN METODE}

\section{Penyiapan Colletotrichum spp.}

Seluruh isolat Colletotrichum spp. yang digunakan merupakan koleksi Klinik Tanaman Departeman Proteksi Tanaman, Fakultas Pertanian, Institut Pertanian Bogor yang dikoleksi pada tahun 2014-2015. Isolat Colletotrichum spp. tersebut terdiri atas tiga spesies yang telah diremajakan pada medium agar-agar dekstrosa kentang (ADK) (Tabel 1). Bahan aktif fungisida yang digunakan adalah fungisidakomersial dari toko pertanian diBogor.

\section{Tingkat Sensitivitas Colletotrichum spp. terhadap Bahan Aktif Fungisida}

Tingkat sensitivitas Colletotrichum spp. ditentukan dari tingkat hambatan relatif bahan aktif fungisida terhadap diameter koloni Colletotrichum spp. pada medium ADK yang dicampur dengan berbagai konsentrasi bahan aktif fungisida dengan metode peracunan medium tumbuh. Konsentrasi bahan aktif yang dipakai berdasarkan konsentrasi anjuran produsen dalam formulasi, yaitu benomil (1000 ppm), klorotalonil (900 ppm), mankozeb (3600 ppm), dan propineb (1000 ppm).

Tabel 1 Sembilan isolat Colletotrichum spp koleksi Klinik Tanaman, IPB.

\begin{tabular}{|c|c|c|}
\hline Spesies & Asal & Galur \\
\hline \multirow{3}{*}{ C. gloeosporioides } & Bandung & BDG 1524 \\
\hline & Tanggamus & TGM 1105 \\
\hline & Bogor & CKB 15 \\
\hline \multirow{3}{*}{ C. acutatum } & Bandung & BDG 1523 \\
\hline & Brebes & BRB 07A \\
\hline & Mojokerto & MJK 02A \\
\hline \multirow{3}{*}{ C. capsici } & Kampar & KMP 1536 \\
\hline & Payakumbuh & PYK 1507 \\
\hline & Bogor & BGR 15103 \\
\hline
\end{tabular}


Konsentrasi bahan aktif dibuat dengan mencampurkan suspensi fungisida ke dalam medium ADK steril dengan suhu $40-45{ }^{\circ} \mathrm{C}$ dalam erlenmeyer dengan takaran sesuai konsentrasi yang diujikan. Sebanyak $10 \mathrm{~mL}$ medium tersebut dituang ke dalam cawan petri sedangkan medium ADK yang tidak dicampur fungisida digunakan sebagai kontrol. Ujung pertumbuhan koloni Colletotrichum spp. dipotong dengan pengebor gabus diameter $0.5 \mathrm{~cm}$ dan diletakkan di tengah cawan petri yang berisi medium perlakuannya (Joshi et al. 2013). Perlakuan diulang sebanyak 4 kali. Pengukuran diameter dilakukan ketika koloni perlakuan kontrol sudah memenuhi cawan. Tingkat hambatan relatif (THR) diameter koloni dihitung menggunakan rumus:

$$
\mathrm{THR}=\frac{\mathrm{d} 1-\mathrm{d} 2}{\mathrm{~d} 1} \times 100 \% \text {, dengan }
$$

d1, diameter koloni patogen uji pada kontrol; d2, diameter koloni pada perlakuan. Data dianalisis menggunakan analisis probit untuk menentukan konsentrasi yang menghambat $50 \%$ pertumbuhan diameter koloni $\left(\mathrm{IC}_{50}\right)$ Colletotrichum spp.

\section{Potensi Perkembangan Resistensi Colletotrichum spp. terhadap Bahan Aktif Fungisida}

Potensi perkembangan resistensi isolat Colletotrichum spp. terhadap bahan aktif fungisida diukur dari perubahan tingkat sensitivitas melalui metode subkultur berulang yang dimulai dari konsentrasi penghambatan relatif $>90 \%$. Koloni disubkulturkan kembali pada medium yang baru dengan konsentrasi yang sama. Tingkat hambatan relatifditentukan dengan metode Joshi et al.(2013). Pengujian ini dihentikan ketika terjadi perubahan tingkat sensitivitas masing-masing Colletotrichum spp. terhadap bahan aktif fungisida yang diujikan. Tingkat sensitivitas Colletotrichum spp. terhadap bahan aktif fungisida ditentukan berdasarkan nilai THR (Kumar et al. 2007), yaitu THR > 90\%, sangat sensitif (SS); 75\% $<$ THR $\leq 90 \%$, sensitif $(\mathrm{S}) ; 60 \%<\mathrm{THR} \leq$ $75 \%$, resisten sedang (RS); $40 \%<\mathrm{THR} \leq$ $60 \%$, resisten $(\mathrm{R}) ; \mathrm{THR} \leq 40 \%$, sangat resisten (SR). Tingkat sensitivitas juga di tentukan pada 5 dan 10 kali konsentrasi anjuran, tingkat sensitivitas pada kosentrasi digunakan untuk menentukan potensi perkembangan resistensi Colletotrichum spp.

THR dianalisis menggunakan piranti lunak SAS 9.0 dengan uji lanjut duncan multiple range test (DMRT) dan dilanjutkan menggunakan program POLO PC untuk mengetahui nilai $\mathrm{IC}_{50}$.

\section{HASIL}

\section{Sensitivitas Colletotrichum spp. terhadap Bahan Aktif Fungisida}

Interaksi antara Colletotrichum spp. dan bahan aktif fungisida berpengaruh terhadap THR (Tabel 1). Berdasarkan tingkat hambatan relatif tersebut, semua Colletotrichum yang diuji sudah menunjukkan reaksi resistensi

Tabel 1 Tingkat hambatan relatif bahan aktif fungisida terhadap Colletotrichum spp pada konsentrasi anjuran

\begin{tabular}{llcccc}
\hline \multirow{2}{*}{ Galur Colletotrichum } & & \multicolumn{4}{c}{ Fungisida $^{\mathrm{a}}$} \\
\cline { 2 - 6 } C. gloeosporioides & BDG 1524 & $100.00 \mathrm{i}$ & $23.91 \mathrm{~cd}$ & $50.21 \mathrm{~d}$ & $60.49 \mathrm{de}$ \\
& TGM 1105 & $100.00 \mathrm{i}$ & $15.01 \mathrm{bc}$ & $48.09 \mathrm{~d}$ & $50.15 \mathrm{~d}$ \\
& CKB 15 & $92.65 \mathrm{~h}$ & $5.62 \mathrm{~b}$ & $41.87 \mathrm{~d}$ & $72.76 \mathrm{f}$ \\
C. acutatum & BDG 1523 & $75.08 \mathrm{f}$ & $15.76 \mathrm{bc}$ & $50.19 \mathrm{~d}$ & $59.13 \mathrm{~d}$ \\
& BRB 07A & $78.74 \mathrm{f}$ & $-1.66 \mathrm{~b}$ & $55.41 \mathrm{~d}$ & $54.64 \mathrm{~d}$ \\
& MJK 02A & $76.77 \mathrm{f}$ & $17.19 \mathrm{abcd}$ & $59.54 \mathrm{~d}$ & $53.06 \mathrm{~d}$ \\
C. capsici & KMP 1536 & $84.00 \mathrm{~g}$ & $-7.37 \mathrm{a}$ & $55.20 \mathrm{~d}$ & $56.45 \mathrm{~d}$ \\
& PYK 1507 & $97.85 \mathrm{i}$ & $29.37 \mathrm{~cd}$ & $35.14 \mathrm{~cd}$ & $53.93 \mathrm{~d}$ \\
& BGR 15103 & $76.02 \mathrm{f}$ & $44.68 \mathrm{~d}$ & $33.75 \mathrm{~cd}$ & $66.57 \mathrm{e}$ \\
\hline
\end{tabular}

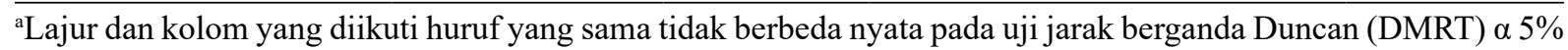


(resisten sampai sangat resisten) terhadap bahan aktif klorotalonil. Semua galur Colletotrichum yang diuji masih dalam kriteria sensitif terhadap bahan aktif benomil, tetapi sudah resisten terhadap bahan aktif mankozeb dan propineb. C. gloeosporioides memiliki tingkat sensitivitas bervariasi hanya terhadap propineb, tetapi pada $C$. capsici variasi tersebut terjadi terhadap semua bahan aktif yang diuji. Semua galur C. acutatum menunjukkan reaksi ketahanan yang sama terhadap semua bahan aktif tersebut (Tabel 2).

Semua galur Colletotrichum yang diuji sudah menunjukkan resistensi terhadap bahan aktif klorotalonil, dan masih sensitif terhadap bahan aktif benomil jika konsentrasinya dinaikkan 5 sampai 10 kali dari anjuran produk komersialnya. Sementara itu, sebagian besar galur Colletotrichum masih sensitif terhadap bahan aktif mankozeb dan propineb jika konsentrasinya ditingkatkan 5 sampai 10 kali dari anjuran (Tabel 3). Tingkat sensitivitas galur Colletotrichum spp. terhadap masing-masing bahan aktif ditandai juga dengan perbedaan perkembangan diameter koloni (Gambar 1).

Bahan aktif benomil memiliki nilai $\mathrm{IC}_{50}$ di bawah konsentrasi anjuran, tetapi nilai $\mathrm{IC}_{50}$ bahan aktif klorotalonil di atas konsentrasi anjuran. Nilai $\mathrm{IC}_{50}$ untuk bahan aktif propineb dan mankozeb berada pada rentang konsentrasi anjuran dan beberapa di bawah anjuran ditampilkan pada Tabel 4.

Tabel 2 Tingkat sensitivitas Colletotrichum spp. terhadap bahan aktif fungisida

\begin{tabular}{llcccc}
\hline \multirow{2}{*}{ Galur Colletotrichum } & \multicolumn{4}{c}{ Sensitivitas $^{\mathrm{a}}$} \\
\cline { 2 - 5 } \multicolumn{1}{c}{ C. gloeosporioides } & BDG 1524 & Benomil & Klorotalonil & Mankozeb & Propineb \\
& TGM 1105 & SS & SR & $\mathrm{R}$ & $\mathrm{RS}$ \\
\multirow{5}{*}{ C. acutatum } & CKB 15 & $\mathrm{SS}$ & $\mathrm{SR}$ & $\mathrm{R}$ & $\mathrm{R}$ \\
& BDG 1523 & $\mathrm{S}$ & $\mathrm{SR}$ & $\mathrm{R}$ & $\mathrm{RS}$ \\
& BRB 07A & $\mathrm{S}$ & $\mathrm{SR}$ & $\mathrm{R}$ & $\mathrm{R}$ \\
C. capsici & MJK 02A & $\mathrm{S}$ & $\mathrm{SR}$ & $\mathrm{R}$ & $\mathrm{R}$ \\
& KMP 1536 & $\mathrm{S}$ & $\mathrm{SR}$ & $\mathrm{R}$ & $\mathrm{R}$ \\
& PYK 1507 & $\mathrm{SS}$ & $\mathrm{SR}$ & $\mathrm{SR}$ & $\mathrm{R}$ \\
& BGR 15103 & $\mathrm{S}$ & $\mathrm{R}$ & $\mathrm{SR}$ & $\mathrm{R}$ \\
\hline
\end{tabular}

aSS, sangat sensitif; S, sensitif; RS, resisten sedang; R, resisten; SR, sangat resisten.

Tabel 3 Tingkat sensitivitas Colletotrichum spp. terhadap bahan aktif fungisida pada tiga konsentrasi

\begin{tabular}{|c|c|c|c|c|c|c|c|c|c|c|c|c|}
\hline \multirow{3}{*}{ Galur Colletotrichum } & \multicolumn{12}{|c|}{ Konsentrasi bahan aktif $^{\mathrm{a}}$} \\
\hline & \multicolumn{3}{|c|}{ Benomil } & \multicolumn{3}{|c|}{ Klorotalonil } & \multicolumn{3}{|c|}{ Mankozeb } & \multicolumn{3}{|c|}{ Propineb } \\
\hline & $1 \mathrm{x}$ & $5 x$ & $10 x$ & $1 \mathrm{x}$ & $5 x$ & $10 \mathrm{x}$ & $1 \mathrm{x}$ & $5 x$ & $10 \mathrm{x}$ & $1 \mathrm{x}$ & $5 x$ & $10 \mathrm{x}$ \\
\hline \multicolumn{13}{|l|}{ C. gloeosporioides } \\
\hline BDG1524 & SS & SS & SS & SR & $\mathrm{R}$ & $\mathrm{R}$ & $\mathrm{R}$ & $\mathrm{S}$ & SS & RS & $\mathrm{S}$ & $\mathrm{S}$ \\
\hline TGM1105 & SS & SS & SS & SR & SR & SR & $\mathrm{R}$ & RS & SS & $\mathrm{R}$ & RS & $\mathrm{S}$ \\
\hline CKB15 & SS & SS & SS & SR & SR & $\mathrm{R}$ & $\mathrm{R}$ & $\mathrm{S}$ & $\mathrm{S}$ & RS & $\mathrm{S}$ & SS \\
\hline \multicolumn{13}{|l|}{ C. acutatum } \\
\hline BDG1523 & $\mathrm{S}$ & SS & SS & SR & SR & SR & $\mathrm{R}$ & $\mathrm{S}$ & SS & $\mathrm{R}$ & RS & $\mathrm{S}$ \\
\hline BRB07 & $\mathrm{S}$ & SS & SS & SR & SR & SR & $\mathrm{R}$ & SS & SS & $\mathrm{R}$ & RS & $\mathrm{S}$ \\
\hline MJK02 & S & SS & SS & SR & $\mathrm{R}$ & $\mathrm{R}$ & $\mathrm{R}$ & RS & SS & $\mathrm{R}$ & $\mathrm{S}$ & S \\
\hline \multicolumn{13}{|l|}{ C. capsici } \\
\hline KMP1536 & $\mathrm{S}$ & SS & SS & SR & SR & SR & $\mathrm{R}$ & SS & SS & $\mathrm{R}$ & RS & $\mathrm{S}$ \\
\hline PYK1507 & SS & SS & SS & SR & SR & SR & SR & $\mathrm{S}$ & $\mathrm{SS}$ & $\mathrm{R}$ & $\mathrm{S}$ & S \\
\hline BGR15103 & $\mathrm{S}$ & SS & $\mathrm{SS}$ & $\mathrm{R}$ & SR & SR & SR & RS & $\mathrm{RS}$ & $\mathrm{RS}$ & $\mathrm{S}$ & $\mathrm{S}$ \\
\hline
\end{tabular}

aSS, sangat sensitif; S, sensitif; RS, resisten sedang; R, resisten; SR, sangat resisten; konsentrasi bahan aktif sesuai anjuran ialah $1 \mathrm{x}$. 


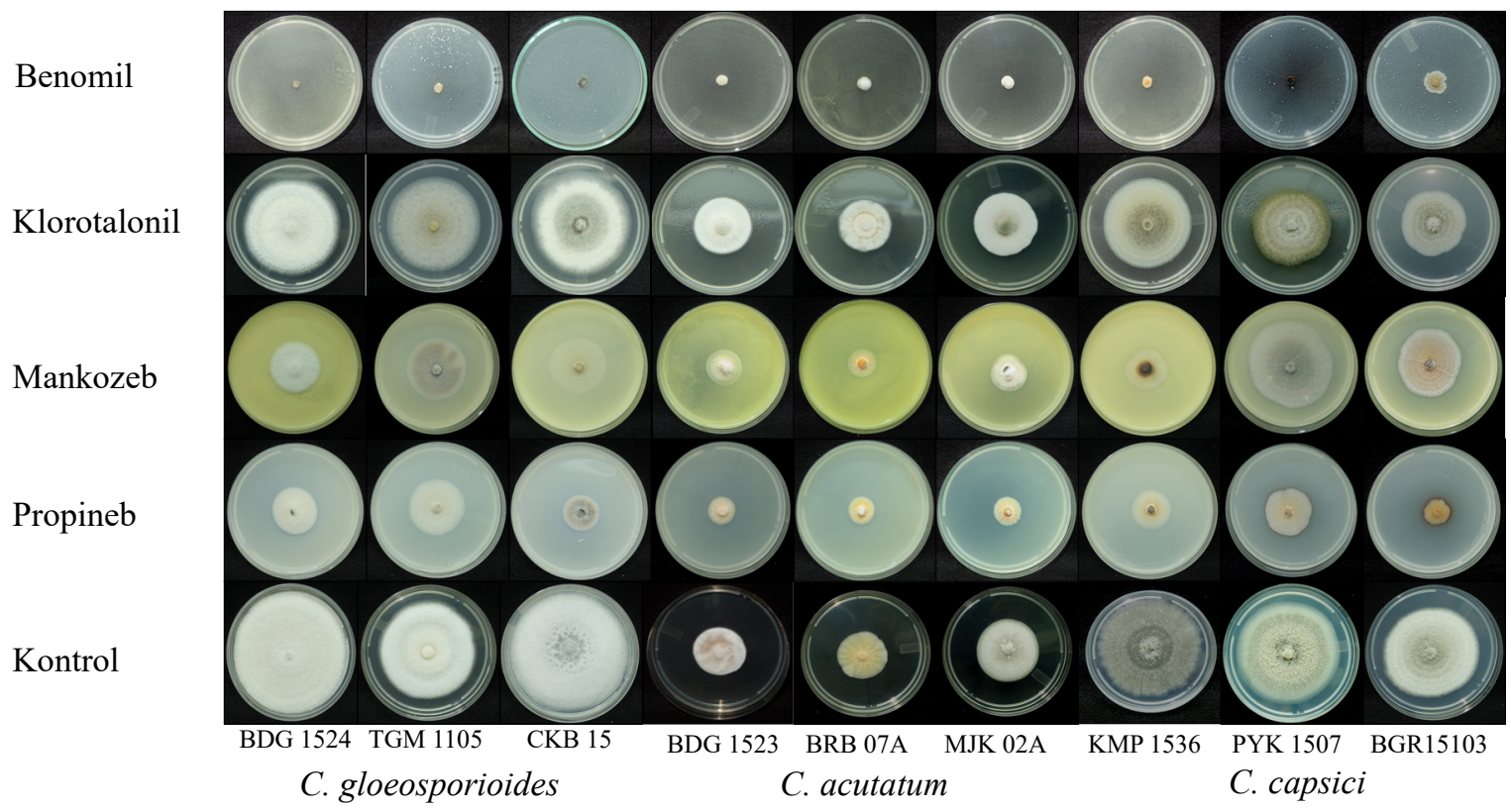

Gambar 1 Perbandingan pertumbuhan diameter koloni Colletotrichum spp. (umur 7 HSI) pada berbagai konsentrasi anjuran bahan aktif fungisida.

Tabel 4 Nilai IC $_{50}$ bahan aktif fungisida terhadap galur Colletotrichum spp.

\begin{tabular}{lccccccccc}
\hline & \multicolumn{8}{c}{ Galur Colletotrichum spp. } \\
\cline { 2 - 10 } Bahan aktif & BDG & TGM & CKB & BDG & BRB & MJK & KMP & PYK & BGR \\
& 1524 & 1105 & 15 & 1523 & $07 A$ & $02 A$ & 1536 & 1507 & 15103 \\
\hline Benomil & 6 & 0 & 2 & 140 & 76 & 127 & 248 & 6 & 139 \\
Klorotalonil & 9925 & 37857 & 17604 & 10090 & 33976 & 14180 & 28360 & 22364 & 28 \\
Mankozeb & 1948 & 3094 & 596 & 2226 & 1496 & 1370 & 1607 & 2969 & 3003 \\
Propineb & 432 & 902 & 190 & 376 & 435 & 358 & 557 & 687 & 449 \\
\hline
\end{tabular}

Tabel 5 Perkembangan resistensi Colletotrichum spp. terhadap bahan aktif fungisida

\begin{tabular}{|c|c|c|c|c|c|c|}
\hline \multirow{2}{*}{ Bahan aktif } & \multirow{2}{*}{\multicolumn{2}{|c|}{ Galur Colletotrichum }} & \multicolumn{4}{|c|}{ Perkembangan reaksi } \\
\hline & & & \multirow{2}{*}{$\begin{array}{c}\begin{array}{c}\text { Kultur } \\
\text { awal }\end{array} \\
\text { SS }\end{array}$} & \multirow{2}{*}{$\begin{array}{c}\begin{array}{c}\text { Subkultur } \\
\text { ke-1 }\end{array} \\
\text { S }\end{array}$} & \multirow{2}{*}{$\begin{array}{c}\begin{array}{c}\text { Subkultur } \\
\text { ke-2 }\end{array} \\
\mathrm{S}\end{array}$} & \multirow{2}{*}{$\begin{array}{c}\begin{array}{c}\text { Subkultur } \\
\text { ke-3 }\end{array} \\
\text { S }\end{array}$} \\
\hline Benomil & C. gloeosporioides & BDG 1524 & & & & \\
\hline & & TGM 1105 & SS & SS & RS & $\mathrm{R}$ \\
\hline & & CKB 15 & SS & $\mathrm{S}$ & $\mathrm{S}$ & RS \\
\hline & C. acutatum & BDG 1523 & SS & $\mathrm{S}$ & $\mathrm{S}$ & $\mathrm{S}$ \\
\hline & & BRB 07A & SS & SS & $\mathrm{S}$ & $\mathrm{S}$ \\
\hline & & MJK 02A & SS & $\mathrm{S}$ & $\mathrm{S}$ & $\mathrm{RS}$ \\
\hline & C. capsici & KMP 1536 & SS & $\mathrm{S}$ & $\mathrm{S}$ & $\mathrm{S}$ \\
\hline & & PYK 1507 & SS & SS & $\mathrm{S}$ & $\mathrm{S}$ \\
\hline & & BGR 15103 & SS & $\mathrm{S}$ & S & $\mathrm{S}$ \\
\hline \multirow[t]{7}{*}{ Mankozeb } & C. gloeosporioides & BDG 1524 & SS & SS & SS & SS \\
\hline & & TGM 1105 & SS & SS & SS & SS \\
\hline & C. acutatum & BDG 1523 & SS & $\mathrm{S}$ & $\mathrm{S}$ & $\mathrm{S}$ \\
\hline & & BRB 07A & SS & SS & SS & SS \\
\hline & & MJK 02A & SS & SS & SS & SS \\
\hline & C. capsici & KMP 1536 & SS & SS & SS & SS \\
\hline & & PYK 1507 & SS & $\mathrm{S}$ & $\mathrm{S}$ & $\mathrm{S}$ \\
\hline Propineb & C. gloeosporioides & CKB 15 & SS & $\mathrm{RS}$ & $\mathrm{R}$ & $\mathrm{R}$ \\
\hline
\end{tabular}

SS, sangat sensitif; S, sensitif; RS, resisten sedang; R, resisten; SR, sangat resisten. 
Perkembangan Resistensi Colletotrichum spp. terhadap Bahan Aktif Fungisida

Potensi perkembangan resistensi terhadap benomil terjadi dengan cepat pada $C$. gloeosporioides TGM 1105. Pada subkultur ke-3 galurinisudahtahan. Galur Colletotrichum spp. lebih lama berkembang menjadi resisten terhadap bahan aktifmankozeb. Perkembangan resistensi terhadap bahan aktif propineb hanya diuji pada C. gloeosporioides CKB 15 saja. C. gloeosporioides CKB 15 sudah resisten terhadap propineb setelah subkultur ke-2 dan ke-3 (Tabel 5).

\section{PEMBAHASAN}

Tingkat hambatan relatif bahan aktif benomil, klorotalonil, mankozeb dan propineb terhadap pertumbuhan koloni galur Colletotrichum spp. uji berbeda-beda. Perbedaan nilai $\mathrm{IC}_{50}$ pada masing-masing bahan aktif menyebabkan adanya perbedaan tingkat sensitivitas. Rendah dan tingginya nilai $\mathrm{IC}_{50}$ suatu bahan aktif dari sensitivitas isolat Colletotrichum spp. disebabkan karena isolat yang digunakan sudah terpapar dalam jangka waktu yang lama dengan bahan aktif tertentu. Cendawan patogen memiliki mekanisme untuk mendegradasi senyawa toksik menjadi senyawa yang kurang toksik atau tidak toksik jika bahan aktif tersebut diaplikasikan secara terus-menerus.

Petani di Indonesia cenderung menggunakan fungisida yang sama bahan aktifnya secara terus-menerus jika pada awal mencoba sudah mengetahui keefektifannya. Ketika keefektifannya menurun maka petani akan meningkatkan konsentrasinya. Pemakaian jenis bahan aktif dalam mengendalikan penyakit antraknosa pada cabai cenderung beragam di setiap daerah. Bahan aktif propineb dan mankozeb digunakan oleh sebagian besar petani di Jawa Barat (Suganda et al. 2001) sedangkan petani di Jawa Tengah, umumnya menggunakan bahan aktif klorotalonil dan mankozeb (Afriyanto et al. 2009)

Perbedaan cara kerja bahan aktif juga memengaruhi tingkat sensitivitas isolat terhadap bahan aktif yang digunakan. Benomil merupakan fungisida sistemik bersifat spesifik mengganggu mitosis $\beta$-tubulin dan pembelahan sel (FRAC 2016). Bahan aktif benomil bersifat eradikan dengan menghambat pertumbuhan miselium sebelum atau setelah infeksi. Bahan aktif ini sering digunakan sebagai perlakuan benih (Setiyowati et al. 2007). Diduga hal tersebut yang menyebabkan isolat Colletotrichum masih sensitif bahkan sangat sensitif terhadap bahan aktif benomil. Benomil dapat dideteksi dari urutan gen $\beta$-tubulin, mutasi akan terjadi pada nukleotida tunggal sehingga menyebabkan perubahan pada kodon 198 atau 200 (Peres et al. 2004).

Mekanisme resistensi pada bahan aktif multi site mode of action belum banyak diteliti karena resistensi yang terjadi akan melibatkan banyak mutasi gen sehingga perubahan pada gen sulit diprediksi (Kumar dan Rani 2013). Klorotalonil, mankozeb, dan propineb merupakan fungisida umum yang bersifat kontak menghambat lebih dari satu situs biokimia organel patogen (FRAC 2016). Kumar et al. (2007) melaporkan fungisida dengan mekanisme multi site mode of action seperti mankozeb secara umum bersifat nonsistemik yang memiliki risiko yang rendah untuk perkembangan resistensi cendawan terhadap bahan aktif tersebut. Resistensi patogen terhadap bahan aktif multi site mode of action propineb terjadi karena patogen terusmenerus terkena paparan bahan aktif tersebut. Patogen dengan siklus penyakit polisiklik seperti Colletotrichum spp. memungkinkan inokulum patogen selalu tersedia sehingga aplikasi fungisida selalu dilakukan sepanjang musim tanam. Hal tersebut memicu timbulnya ketahanan patogen terhadap fungisida yang diaplikasikan (Lim dan Choi 2006). Aplikasi fungisida dilakukan secara terjadwal dengan selang waktu 7-10 hari sehingga risiko terpaparnya patogen terhadap fungisida terjadi sepanjang musim tanam. Hal ini menyebabkan munculnya resistensi patogen yang tinggi dan dipengaruhi oleh penggunaan fungisida dengan bahan aktif yang sama sepanjang musim tanam (Darajat 2014).

Perbedaan tingkat sensitivitas antarisolat pada spesies yang sama disebabkan karena 
isolat yang digunakan berasal dari daerah yang berbeda. Perbedaan frekuensi apikasi juga memengaruhi tingkat sensitivitas galur patogen terhadap bahan aktif fungisida (Kumar et al. 2007; Joshi et al. 2013). Respons sensitivitas yang berbeda terjadi pada setiap spesies penyebab antraknosa yang diisolasi dari daerah di Lembang Jawa Barat (Suganda et al. 2001). Keragaman genetik setiap spesies diduga juga memengaruhi respons sentisitivitasnya terhadap bahan aktif fungisida. Ketahanan cenderung terjadi pada patogen yang mempunyai tingkat keragaman genetik dan adaptasi yang tinggi (Kumar dan Rani 2013). Menurut Suganda et al.(2001) perlu dilakukan rotasi pemakaian fungisida terutama dilihat dari cara kerja dan bahan aktif agar ketahanan isolat Colletotrichum spp. dapat ditekan.

Beberapa bahan aktif fungisida cenderung sudah tidak efektif terhadap Colletotrichum spp. penyebab antraknosa cabai di daerah sentra penanaman cabai di Jawa dan Sumatera. Fungisida yang bersifat sistemik masih efektif untuk Colletotrichum spp. tetapi dapat memicu terjadinya ketahanan dengan cepat sehingga tidak dianjurkan dilakukan secara intensif.

\section{DAFTAR PUSTAKA}

Afriyanto, Nurjazuli, Budiyono. 2008. Kajian keracunan pestisida pada petani penyemprot cabe di Desa Candi Kecamatan Bandungan Kabupaten Semarang. J Kesling Indones. 8(1):10-20.

[BPS] Badan Pusat Statistik. 2015. Statistik Indonesia Statistical Yearbook of Indonesia 2015. Jakarta (ID):BPS Indonesia.

[Dirjen PSP] Direktorat Jenderal Sarana dan Prasarana Pertanian. 2015. Pestisida Pertanian dan Kehutan Terdaftar 2014. Jakarta (ID): Dirjen PSP.

[FRAC] Fungicide Resistance Action Committe. 2015. FRAC Code List $($ *2015: Fungicides sorted by mode of action (including FRAC Codenumbering) [Internet]. [diunduh 2016 Agu 4]. Tersedia pada: http: //www.frac.info/docs/defaultsource/publications/frac-code-list/frac- code-list- 2015 final C2AD7 AA36764. pdf? Sfvrsn=4.

Darajat YM. 2014. Perbandingan pola penggunaan pestisida pada petani sayuran dan petani tanaman hias di kecamatan Cipanas kabupaten Cianjur. [Skripsi]. Bogor (ID): Institut Pertanian Bogor.

Herwidyarti KH, Ratih S, Resiworo DJS. 2013.

Keparahan penyakit antraknosa pada cabai (Capsicum annuum L) dan berbagai jenis gulma. J Agrotek Trop. 1(1):102-106.

Joshi MS, Sawant DM, Gaikwad AP. 2013. Variation in fungi toxicant sensitivity of Colletotrichum gloeosporioides isolates infecting fruit crops. J Food Agric Sci. 3(1):6-8. DOI: 10.5897/ISABBJFAS11.042.

Kim SH, Yoon JB, Do JW, Park HG. 2007. Resistance to anthracnose caused by Colletotrichum acutatum in chilli pepper (Capsicum annuum L.). J Crop Sci Biotech. 10(4):277-280.

Kumar AS, Eswara NPR, Hariprasad KR, Devi MC. 2007. Evaluation of fungicidal resistance among Colletotrichum gloeosporioides isolates causing mango anthracnose in agri export zone of Andhra Pradesh India. Plant Pathol Bull. 6(3):157160.

Kumar S, Rani A. 2013. Fungicide resistance: a major challenge in plant disease control. Int J App Biosci. 1(3):35-47.

Lim TH, Choi YH. 2006. Response of several fungicides of Colletotrichum gloeosporioides isolates obtained from persimmons in Sangju. Kor J Plant Pathol. 12(22):99-10.

Prathiba VH, Rao AM, Ramesh S, Nanda C. 2013. Estimation of fruit quality parameter in anthracnose infected chili fruits. Int $J$ Agric Food Sci Technol. 4(2):57-60.

Peres NAR, Souza NL, Peever TL, Timmer LW. 2004. Benomyl sensitivity of isolates of Colletotrichum acutatum and C. gloeosporioides from citrus. Plant Dis. 88(2):125-130. DOI: https://doi. org/10.1094/PDIS.2004.88.2.125.

Sangdee A, Sachan S, Khankhum S. 2011. Morphological, pathological and 
molecular variability of Colletotrichum capsici causing anthracnose of chilli in the North-East of Thailand. Afr J Microbiol. 5(25):4368-4372. DOI: https://doi. org/10.5897/AJMR11.476.

Setiyowati H, Surahman M, Wiyono S. 2007. Pengaruh seed coating dengan fungisida benomil dan tepung cúrcuma terhadap patogen antraknosa terbawa benih dan viabilitas benih cabai besar (Capsicum annuum L.). J Agron Indones. 35(3):176182.

SugandaT, YuliaE, Hidayat Y. 2001. Variabilitas sensitivitas jamur Colletotrichum spp. asal sentra pertanaman cabai merah Jawa Barat terhadap beberapa bahan aktif fungisida. J Agrikultur. 12:122-129.
Syukur M, Sujiprihati S, Yunianti R, Kusumah DA. 2010. Evaluasi daya hasil cabai hibrida dan daya adaptasinyadiempat lokasi dalam dua tahun. J Agron Indones. (38)1:43-51.

Widodo. 2007. Status of chili anthracnose in Indonesia. First International Symposium on Chili Anthracnose; 2007 September 17-19; Seoul. Seoul (KR): Seoul National University.

Ziogas BN, Markoglou AN, Spyropoulou V. 2005. Effect to phenylpyrrole resistance mutations on ecological fitness of Botrytis cinerea and their genetical basis in Ustilago maydis. Eur J Plant Pathol. 1(113):83-100. DOI: https://doi.org/10.1007/s10658-0051227-7. 